\title{
IGURAS DEL DESARRAIGO: LOS CICLOS
CAMINANTES E HILATURAS DE VÍCTOR MIRA
}

\author{
DAVID CORTÉS SANTAMARTA
}

Universidad Complutense de Madrid davcortes@yahoo.es

\begin{abstract}
Resumen: El presente texto analiza la iconografía de dos conjuntos de obras realizados por el artista español Víctor Mira (1949-2003) a lo largo de la primera mitad de la década de 1980. En la atormentada condición de las figuras no sólo se transmite la inquietud existencial del propio Mira, sino que también se cifran alusiones a las dos tradiciones culturales, las de Alemania y España, donde desarrolló su trayectoria creativa. Por el inmediato dramatismo de su lenguaje plástico, su densidad simbólica y el decidido uso del medio pictórico para reflexionar en torno a la propia identidad y a la historia contemporánea, la obra de Mira, dentro de las denominadas tendencias neoexpresionistas que dominaron la pintura europea en aquellos años, está próxima a la de autores del ámbito alemán, como Baselitz, Kiefer, Penck o Immendorff.
\end{abstract}

Palabras clave: Víctor Mira / Neoexpresionismo / Iconografía / Grotesco / Wanderer.

Abstract: The present text analyses the iconography of two cycles of works created by the Spanish artist Víctor Mira (1949-2003) throughout the first part of the 1980s. The tortured condition of the figures not only transmits the existential unrest of the author, but also includes allusions to the two cultural traditions, German and Spanish, where Mira developed his creative work. Due to the dramatic intensity and symbolic density of his artistic language and his resolute use of the pictorial medium to reflect around one's identity and contemporary history, Víctor Mira's work, defined within the so-called Neo-Expressionist movement which dominated European painting in those years, is close to the work of German painters, such as Baselitz, Kiefer, Penck or Immendorff.

Key words: Víctor Mira / Neo-Expressionism / Iconography / Grotesque / Wanderer.

\section{Introducción}

Pintados a lo largo de la primera mitad de la década de 1980, los ciclos Caminantes e Hilaturas ocupan una posición similar en la trayectoria del artista español Víctor Mira (1949-2003), lo que justifica su análisis conjunto. En la atormentada condición de las figuras de ambos conjuntos no sólo se transmite la inquietud existencial del propio Mira, sino que también se cifran alusiones a las dos tradiciones culturales, la española y la alemana, donde desarrolló su trayectoria creativa. Si bien el inicio de ésta se sitúa en Zaragoza, Madrid y, posteriormente, Barcelona, las estancias de Mira en Alemania, iniciadas a partir de 1975, y cada vez más frecuentes, hasta establecerse en Múnich en 1988, le permitieron un temprano contacto con la obra de artistas como Joseph Beuys o
Georg Baselitz, a la vez que una plena inmersión en aquellas corrientes pictóricas que habrían de calificarse como neoexpresionistas, a la que pertenecen A. R. Penck, Anselm Kiefer, Markus Lüpertz o Jörg Immendorff. Aún en sus diferencias estilísticas, la obra de estos creadores afirma las posibilidades de la práctica pictórica para indagar críticamente en torno a la problemática identidad nacional y a la convulsa historia contemporánea de Alemania, a través de un lenguaje eminentemente figurativo, dotado de una especial densidad simbólica. Las series Caminantes e Hilaturas de Mira manifiestan su proximidad a tales planteamientos que, en su caso, se combinan además con explícitas alusiones a la tradición de la pintura española y a la propia coyuntura de un país en plena transición política, tras la dictadura franquista. En su singular integración de esas dimensiones críti-

Fecha de recepción: 15 de abril de 2017 / Fecha de aceptación: 14 de septiembre de 2017. 
cas, que no harán sino profundizarse en ciclos posteriores, como Interior español con exterior holandés, la pintura de Mira se adecúa más a las coordenadas dominantes en el contexto artístico germano que a las presentes en los pintores españoles de su misma generación.

La obra de Mira aparece asimismo atravesada por un intenso desgarro existencial que se extiende a sus numerosos textos y declaraciones. Buena parte de la bibliografía sobre el artista está dominada por la imagen del artista maldito. No se trata de cuestionar esa oscura subjetividad en conflicto -el suicidio de Mira en la localidad bávara de Seefeld, en 2003, no fue sino la dramática confirmación de esas pulsiones autodestructivas- que confiere a su creación un turbador sentido, sino de incorporarla a un análisis preciso de la obra, que dé cuenta de la complejidad de una iconografía que el historiador Joachim Petersen ha descrito como "hermética". ${ }^{1}$

Los ciclos Caminantes e Hilaturas proceden de aquellas series donde el artista, desde 1978, había desarrollado un lenguaje plástico de resonancias prehistóricas. El diálogo de Mira con el arte primigenio se mostraba tanto en la rotundidad y simplificación formal de las imágenes como en la profundización de sus connotaciones simbólicas, para constituir una especie de cosmogonía que unía lo remoto y la contemporaneidad. Aunque de esa etapa derivan ciertos procedimientos y referencias, los dos motivos dominantes en los ciclos Caminantes e Hilaturas se emancipan hasta convertirse en plenamente autónomos. A partir de ellos, Mira despliega numerosas variantes en dibujos, estampas y pinturas. Asimismo, la dislocada presencia de las dos figuras antropomorfas parecen apuntar a unos ámbitos significativos comunes.

En su conjunción se ponen de relieve algunas de las características esenciales de ambos conjuntos. No sólo los gruesos contornos que perfilan las concluyentes siluetas de los caminantes (Fig. 1) adquieren una rotundidad mayor al compararlos con la desmaterializada sustancia de las hilaturas (Fig. 2) y se acentúa la agitación gráfica de los disociados trazos de éstas, sino que además, en esa convergencia, se manifiesta la análoga postura corporal de los dos motivos. La torsión extrema que pliega con violencia la cabeza del caminante, hasta volverla completamente del revés, resulta equivalente al giro que también somete a la más equívoca y extraña conformación de las hilaturas. Una misma línea curva tuerce y tensa lo que se correspondería con el cuello de los dos seres. Esa exagerada solución formal cancela aquello que de anecdótico pudiera haber en el gesto de inclinar la cabeza sobre el pecho, como síntoma de tristeza o sumisión, para convertir las figuras en cifras de una irrevocable fractura vital. No se trata de una actitud circunstancial o transitoria, susceptible de ser alterada, sino de una concluyente disposición.

Es en las distintas resoluciones plásticas de cada una de las series -inmediata y cruda en el caso de Caminantes, múltiple y discontinua en el de Hilaturas- desde donde se puede indagar en la especificidad de sus respectivos sentidos. Incluso podría afirmarse que la propia práctica pictórica, en buena medida, genera las figuras. El proceso creativo de Mira resulta especialmente revelador. Las decisiones formales del artista se aprecian con nitidez al examinar las obras iniciales de ambos ciclos, fechadas en los años 1980 y 1981, y sus posteriores transformaciones, que establecen una secuencia impulsada tanto por la eliminación del evidente carácter humano todavía visible en esos primeros ejemplos, como por una progresiva simplificación gráfica, que conducirá a las versiones más características de los mismos.

\section{Ciclo Caminantes}

El origen de la serie Caminantes parece situarse en el enorme óleo Detalle de una marcha (Fig. 3), una de las pinturas pertenecientes a las obras de inspiración prehistórica. Entre los personajes que integran ese grupo migratorio que se desplaza en la "marcha" a la que se refiere el título y que ocupa por completo, en su firme movimiento de derecha a izquierda, la superficie del lienzo, se distinguen varias figuras portando velas e iluminando el trayecto. El sentido grotesco que las define, con un tosco rictus y unos gigantescos ojos circulares burdamente trazados en sus rostros es, junto a la presencia de las velas, el punto de partida para Caminantes.

Que Mira nunca expusiera el lienzo en público, así como el hecho de que posteriormente no retomara la escena general, sino tan sólo algunos de los

1 MIRA, Víctor; PETERSEN, Joachim, Madre Zaragoza. Zaragoza: Diputación de Zaragoza, 1990, p. 15. El propósito de mi tesis doctoral, en curso de realización, responde a la necesidad de examinar en profundidad, desde un planteamiento académico, la iconografía y el lenguaje artístico de los principales ciclos de la obra de Mira. Agradezco a José Manuel Cruz Valdovinos, Catedrático de Historia del Arte de la UCM, su lectura y sus valiosos comentarios al presente estudio. 


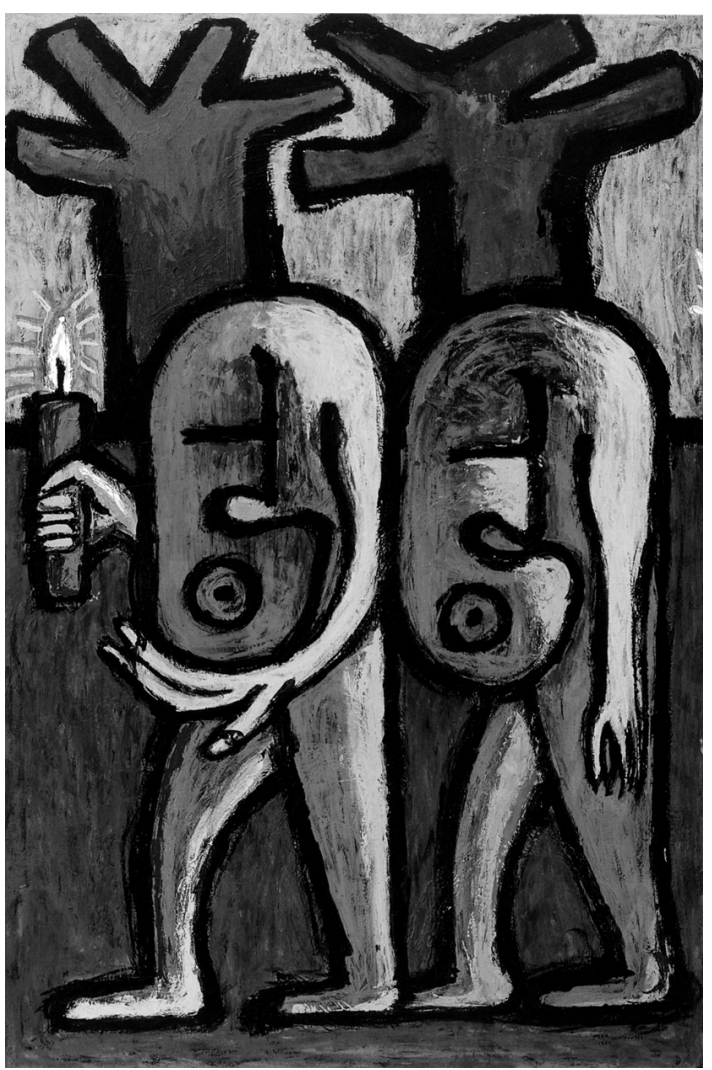

Fig. 1. Víctor Mira. Caminantes, 1984, óleo sobre lienzo, $195 \times 130 \mathrm{~cm}$. Col. particular.

personajes -como los que darían lugar a Caminantes o los perfiles que desembocarían en la serie Sísifo sopla (1984)- hacen pensar que este óleo funcionó en la creación del artista más como un inicial repertorio iconográfico del que extraer motivos que como una obra de carácter definitivo. Tanto su carácter narrativo, que puede ser considerado como una alusión a la vida nómada de los primeros grupos humanos, como los geométricos patrones ornamentales -puntos, trazos paralelos, diseños laberínticos- inscritos en los personajes, serían abandonados en el resto de aquellas obras, de formas más esenciales y sintetizadas, donde Mira propuso su personal interpretación de una iconografía primigenia.

Otras dimensiones sí encontrarán continuidad en la trayectoria de Mira, precisamente en el ciclo Caminantes. Así la ruda fisonomía, caricaturizada, de los personajes, o el sentido de angustiada alarma de la escena, apreciable en la sintetizada expresión de temor que domina sus rostros -hasta convertirlos en una mueca-, y en el apresurado avance de los personajes, que parece que huyen de alguna amenaza o peligro situados más allá de los límites del cuadro. Los acentuados perfiles de

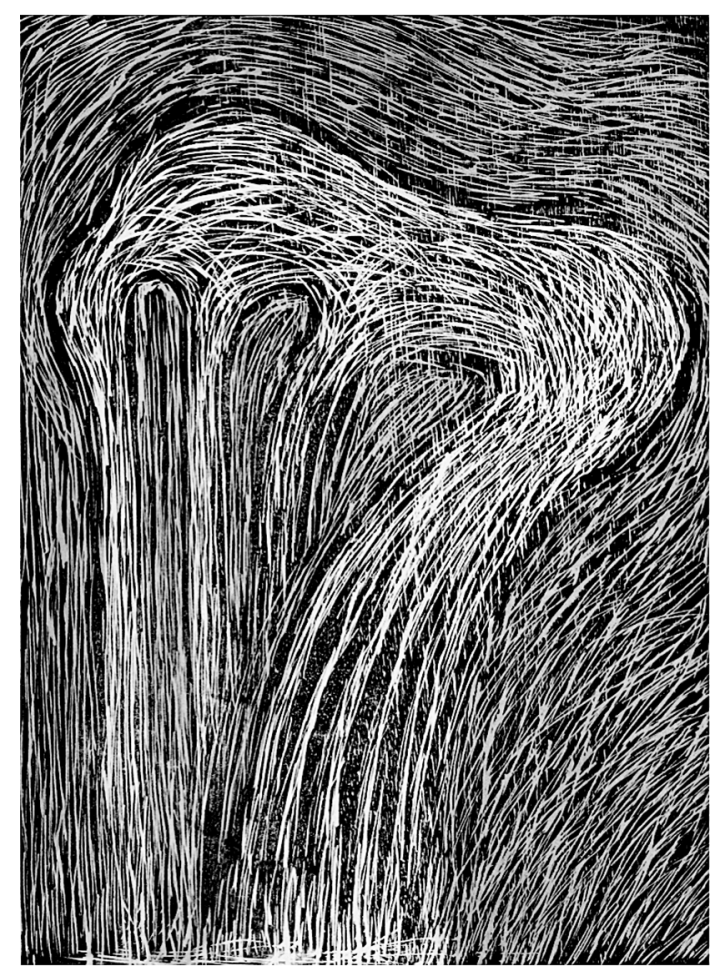

Fig. 2. Víctor Mira. Hilatura, 1985, xilografía, 55 x 39.5 cm. Col. particular.

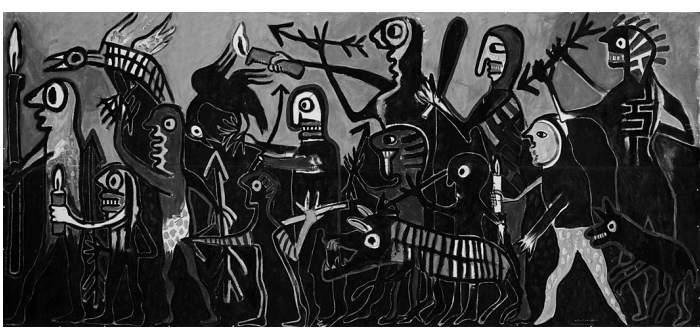

Fig. 3. Víctor Mira. Detalle de una marcha, 1980-1981, óleo sobre lienzo, 210 x $485 \mathrm{~cm}$. Col. particular.

las figuras y la disposición anatómica de los Caminantes, cuyo arcaico y artificial esquematismo recuerda las soluciones formales del arte egipcio, especialmente las de la denominada ley de la frontalidad, provienen también de este lienzo.

Destaca en la ejecución plástica de los Caminantes (Fig. 4) una suerte de crudeza que Mira conduce hasta sus últimas consecuencias. Los colores vivos, aplicados con especial violencia mediante enérgicas pinceladas, en el caso de los óleos o con entintados planos, sin matices, en las estampas, se intensifican mutuamente a través de agrios e hirientes contrastes cromáticos. El pintor extrae del color unas estridentes posibilidades expresivas que refuerzan el impacto agresivo que contienen las obras. Los contornos de las siluetas han sido perfilados con extrema contundencia. Los insistentes 


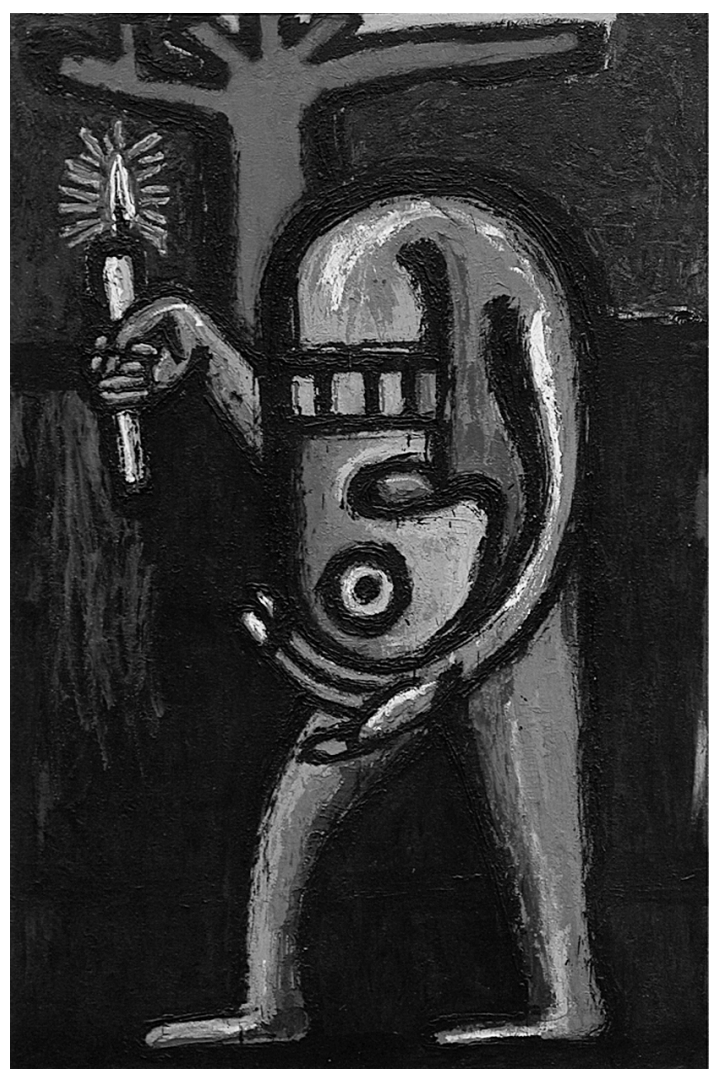

Fig. 4. Víctor Mira. Caminante, 1984, óleo sobre lienzo, 198 x $133.5 \mathrm{~cm}$. Museo Pablo Serrano, Zaragoza.

brochazos negros acentúan el grafismo de las figuras, que adquieren su concluyente potencia gracias precisamente a esa carga matérica, ya sea pigmento o carborundo, acumulado en gruesas y compactas capas. Sin duda es la brutal dislocación que exhiben la que acapara por completo la mirada del espectador. Lo que en las versiones iniciales era un notable giro del cuello de los personajes, se convierte, ya definitivamente, en la inversión absoluta de la cabeza, de tal manera que ésta se integra con tosquedad en el propio cuerpo, ocupando por completo el lugar del torso. La cabeza ha sido, además, hipertrofiada. Las convenciones naturalistas son excluidas a favor de un tratamiento formal de terminante sencillez que transmite -a pesar de ser el resultado de un aquilatado proceso de condensación- una especial ferocidad.

Aunque la totalidad de la figura posee una tensa articulación, activada por unas líneas vigorosa- mente interrelacionadas, su efecto es, sin embargo, el de una inmediatez casi grosera. El modo en el que Mira resuelve la fisonomía de ese rostro del revés está ganado asimismo por una deliberada torpeza. La sencilla retícula de irregulares cuadrados que dibuja la boca de los personajes es, junto con la cabeza invertida, lo que lleva al límite su apariencia grotesca. Mira realiza una áspera traslación gráfica del rictus, ese gesto que consiste en contraer los labios, dejando al descubierto los dientes, por lo que la boca adquiere el aspecto de una risa forzada. $Y$ es en ese rictus donde se convoca con exactitud lo grotesco como categoría estética, que aúna en sí, paradójicamente, los extremos de la risa y del horror. ${ }^{2}$ No sólo la mueca de los Caminantes integra esos dos límites, sino que la misma configuración de los personajes provoca en el espectador ambas reacciones. Hay algo risible en ese ser que avanza con dificultad y arrastra el peso de su enorme cabeza -hasta el punto de que incluso en algunas versiones parece que necesitara sostenerla con una de sus manos- y cuyos ojos desmesuradamente abiertos miran en dirección contraria a la de su marcha. Pero a la vez el sufrimiento que transcribe, aún en su tosco enunciado, ese cuerpo dislocado, así como la errancia a la que está condenado, transmiten, en su convergencia, una intensa angustia.

Cabe interpretar el énfasis en alcanzar una fórmula plástica esencial y concisa de un motivo cuya exagerada deformidad manifieste con aspereza el desgarro vital del personaje, como un intento del artista por contrarrestar el exceso metafórico que inmediatamente se asocia a las representaciones del caminante, un topos visual, musical y literario que, en sus numerosas vertientes, ha atravesado la cultura occidental. Se trataría pues de acotar qué dimensiones de esa extensa tradición resultan pertinentes en un análisis del ciclo de Mira.

Si bien la vela que sujetan los personajes para iluminarse en su trayecto puede estar inicialmente justificada, en una obra como Detalle de una marcha, por el contexto de una escena que alude a los estadios iniciales de la humanidad, en los que el control del fuego supuso un acontecimiento clave, la permanencia y continuidad de la misma en las versiones posteriores de los Caminantes muestra una evidente afinidad con algunas obras

\footnotetext{
2 Entre la numerosa bibliografía dedicada a lo grotesco, destacan, en un análisis próximo al sentido aquí utilizado del término, el clásico KAYSER, Wolfgang. Lo grotesco. Su realización en literatura y pintura. Madrid: Antonio Machado, 2010, así como los estudios de HARPHAM, Geoffrey G. On the Grotesque: Strategies of Contradiction in Art and Literature. Princeton: Princeton University Press, 1982 y CONNELLY, Frances S. Lo grotesco en el arte y la literatura occidentales. La imagen en juego. Madrid: Antonio Machado, 2015.
} 
de Joan Ponç, un autor cuya influencia sobre Mira ya se manifestaba en las series de mediados de la década de 1970, en especial Buosbager o Lugares de la tierra. Muchos personajes de Ponç portan velas con las que intentan alumbrarse y orientarse en su decurso, pero quizá donde mejor se perciba la similitud que guardan los Caminantes de Mira con ellos sea en el óleo Lucha interior (ca. 19701974, óleo sobre tela, $200 \times 499 \mathrm{~cm}$ ), en el que el artista catalán conjura sus escisiones y angustia mediante el agresivo enfrentamiento de unas espasmódicas y crispadas figuras, dos de las cuales sostienen grandes velas, rodeadas de una opresiva atmósfera que la esmaltada superficie del lienzo, con el pigmento aplicado a través de minuciosas pinceladas y una meticulosa descomposición cromática, hace aún más gélida e hiriente. ${ }^{3}$ El personaje que se ilumina con una vela o un farol deriva de la conocida anécdota del filósofo cínico Diógenes de Sínope, que se paseaba por el ágora de Atenas con un farol en pleno día, a la búsqueda de un verdadero hombre, ${ }^{4}$ de manera que el motivo plástico parece adquirir, en las obras de Ponç y de Mira, el sentido de una solitaria indagación o búsqueda existencial que se revela infructuosa.

El paisaje en el ciclo de Mira se ajusta, en sus diversas variantes, a un monótono y sencillo esquema. Una terminante línea de horizonte divide el fondo en dos zonas y de ella surgen las siluetas de uno o dos árboles, cuyo número generalmente se corresponde con el de las figuras antropomorfas. Mira los traza con análoga contundencia, reduciéndolos a una fórmula básica y concisa. Si bien tal escenario puede considerarse una genérica representación de una naturaleza inhóspita y desolada por la que se desplazan los caminantes, sus semejanzas formales con un lienzo de van Gogh que Mira admiraba, Autorretrato camino a Tarascón (Fig. 5), son lo suficientemente notorias -la figura, situada en el centro de la imagen, que avanza por el paisaje, enmarcada por los árboles- como para considerarlo asimismo un referente iconográfico de los Caminantes, que el artista ha integrado hasta tal punto en su propio lenguaje plástico que la alusión original queda asimilada por completo. Mira describía la pintura de van Gogh desde un planteamiento eminentemente trágico: "El aislamiento aquí del artista es tan gráfico que se percibe con auténtica nitidez un autorretrato desesperado (...) ¿pero a dónde se dirige

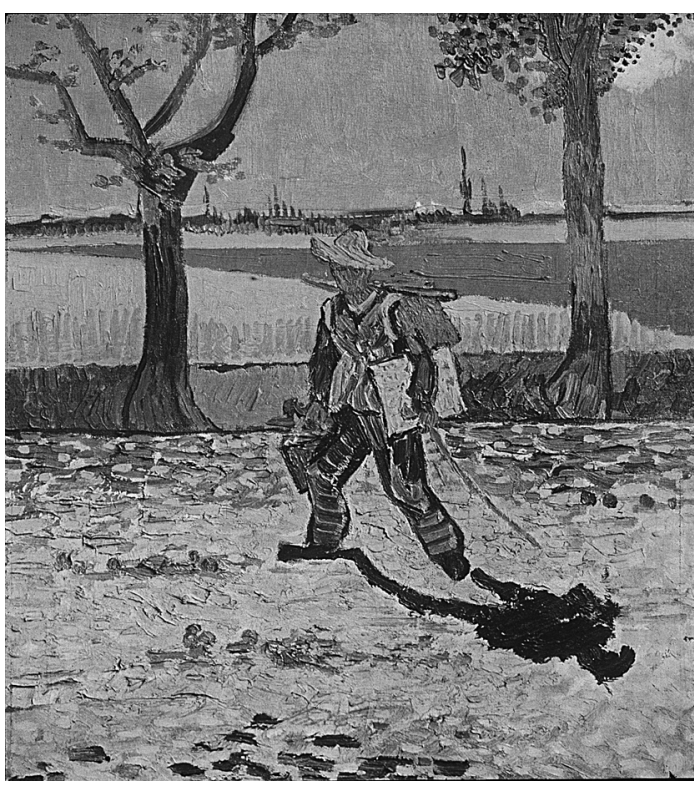

Fig. 5. Vincent van Gogh. Autorretrato camino a Tarascón 1888, óleo sobre lienzo, 44 x $48 \mathrm{~cm}$. Destruido durante la Segunda Guerra Mundial.

van Gogh, sin alegría, con los cachivaches a su espalda como si fueran excrementos? (...) uno, ante ese cuadro, percibe que el artista está haciendo lo correcto en la certeza de que algo terrible le va a ser desvelado". 5

Las dimensiones que Mira destaca en el autorretrato de van Gogh -la tristeza, la soledad o la latente amenaza- se advierten con claridad en las obras del ciclo Caminantes y deben ser integradas en la interpretación de éste. Mira ha reforzado el aislamiento de los caminantes mediante los gruesos contornos que los delimitan, encerrándolos sobre sí mismos, lo que, junto a su actitud formalizada y reiterativa, anula cualquier sugerencia de comunicación entre ellos, incluso en las variantes, muy numerosas, con una pareja de caminantes, cuyas figuras se solapan. Tal proximidad expone aún más la perturbadora clausura que les constriñe: su extrañamiento entre ellos y respecto al propio paisaje.

Al interrogarse sobre el lugar al que se dirige van Gogh, Mira parece indicar uno de los aspectos esenciales de los caminantes, como es la ausencia de cualquier coordenada en el lienzo que aluda al origen o destino de su desplazarse, si bien su distorsión corporal proclama una forzada errancia, que les constituye esencialmente. El título elegido

\footnotetext{
3 Véase LUBAR, Robert S. Joan Ponç. Barcelona: Polígrafa, 1994.

${ }^{4}$ Sobre Diógenes y los filósofos cínicos véase GARCíA GUAL, Carlos. La secta del perro. Madrid: Alianza, 1987.

${ }^{5}$ Carta de Víctor Mira al autor del presente estudio, fechada el 24 de junio de 2000.
} 


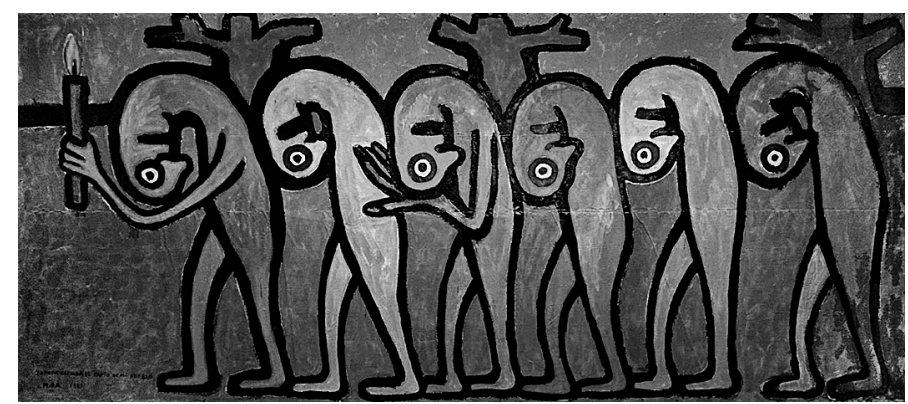

Fig. 6. Víctor Mira. Europa, escucha el canto de mi pueblo, 1981, óleo sobre lienzo, 217 x $500 \mathrm{~cm}$. Col. particular.

por Mira transcribe con literalidad el término alemán Wanderer, con el que se denomina una figura clave en la cultura romántica germana, cuya presencia se extiende desde la novela Wilhelm Meisters Lehrjahre de Goethe hasta su uso como metáfora filosófica por parte de Nietzsche, pasando por las diversas partituras de Franz Schubert -el lied Der Wanderer, el ciclo Winterreise o la Wanderer-Fantasie, para piano, entre otras- o los lienzos de C. D. Friedrich. ${ }^{6}$ De este modo los Caminantes supondrían un ejemplo temprano del diálogo que Mira, al instalarse en Alemania, propone con las referencias culturales del país, transformándolas en motivos plásticos.

El vagar del Wanderer, que no responde ya a un propósito, sino que forma parte de su identidad, asume, en el contexto romántico, diversas inflexiones. Su soledad y desarraigo suponen un decidido alejamiento de las convenciones sociales $y$, en ese sentido, el logro de una subjetividad emancipada, pero asimismo, debido a esa misma exclusión, tal subjetividad no puede ser sino sufriente. Si bien los paisajes son los escenarios privilegiados de su viaje, la naturaleza -en cuya infinitud se revela lo sublime- rara vez es para ellos un refugio. El caminante del Winterreise de Schubert está rodeado de indicios de la muerte, en cada uno de sus pasos sobre la nieve no hace sino emplazar su propio fin. Que años después Mira realizase un amplio ciclo de obras, El monje frente al mar bien temperado, a partir de una de las más célebres obras de Friedrich, donde unas huellas -como resto o señal del caminar- se convierten en el motivo plástico principal, no hace sino confirmar este vínculo de los Caminantes con una tradición romántica que Mira convocará de manera explícita en varios momentos de su trayectoria, ${ }^{7}$ para recuperarla a finales del siglo $X X$ desde unos parámetros que, a la vez que recogen algunas de sus dimensiones, los cuestionan. Las figuras de Mira no poseen ese componente heroico que, en su exceso emocional, albergaban los caminantes románticos. Su quebrantamiento es tal que resulta incluso difícil calificarlos como sujetos. Su descoyuntada apariencia y deliberado tratamiento grosero lo recusan. Una mueca es ya su única expresión.

En el proceso que conduce a las versiones definitivas de los Caminantes hay que destacar, además de Detalle de una marcha, otro óleo de gran tamaño fechado en 1981, Europa, escucha el canto de mi pueblo (Fig. 6), donde surge ya ostensiblemente el recurso que habrá de determinar la formulación plástica final de los Caminantes, como es el radical giro de la cabeza. Frente a las variantes posteriores, en los que Mira incluye una o dos figuras, ${ }^{8}$ la pintura destaca por la inédita cantidad de personajes que, a modo de friso procesional, establecen un iterativo ritmo formal mediante la casi exacta réplica de sus nítidas siluetas. Quizá fuera su cierta uniformidad compositiva, consecuencia de una excesivamente monótona repetición, que no logra articular con plenitud la extensa superficie horizontal del lienzo, lo que llevó a Mira a abandonar esta solución, optando por re-

\footnotetext{
${ }^{6}$ Para un análisis de la figura del Wanderer en la literatura alemana del siglo XIX véase CUSACK, Andrew. The Wanderer in Nineteenth-Century German Literature: Intellectual History and Cultural Criticism. Rochester: Camden House, 2008. En Nietzsche las referencias al Wanderer aparecen principalmente en El caminante y su sombra, en NIETZSCHE, Friedrich. El nacimiento de la tragedia, El caminante y su sombra, La Ciencia Jovial. Madrid: Gredos, 2014. Con respecto a la música de Schubert, puede consultarse PERRY, Jeffrey. "The Wanderer's Many Returns: Schubert's Variations Reconsidered". Journal of Musicology, 2002, n 19, pp. 374-416, así como YOUENS, Susan. Retracing A Winter's Journey. Ithaca y Londres: Cornell University Press, 1991. Sobre Friedrich véase el clásico estudio HOFFMANN, Werner. C. D. Friedrich. Londres: Thames and Hudson, 2001 y KOERNER, Joseph Leo. Caspar David Friedrich and the Subject of Landscape. Londres: Reaktion Books, 2009.

7 Además del ciclo El monje frente al mar bien temperado, realizado principalmente entre 1997 y 2003 , cabe destacar la serie en torno a la Sinfonía $n^{\circ} 5$ de Ludwig van Beethoven, pintada a lo largo de la década de 1990. Sobre esta última véase CORTÉS SANTAMARTA, David. "Pintura y música en la obra de Víctor Mira: el ciclo Beethoven Quinta Sinfonía". Anuario del Departamento de Historia y Teoría del Arte, 2015, vol. 27, pp. 191-211.

8 Excepcionalmente en algunas variantes aparecen tres figuras, como en Familia de caminantes (1984, óleo sobre papel, $109 \mathrm{x}$ $81.5 \mathrm{~cm}$. Col. particular), cuya denominación también varía respecto al título genérico de la serie. Más individualizadas de lo habitual -hasta el punto de que una de ellas, por su tamaño y el gesto protector de la que la acompaña, posee un marcado carácter infantil- cabe identificarlas como una traslación pictórica de la propia familia del artista.
} 
ducir el número de personajes y por un generalizado uso de formatos verticales. Sin embargo, la obra reviste un especial interés, ya que además de iluminar una fase de la elaboración del motivo, posee asimismo un título en el que se vislumbra, con una claridad mucho mayor que en el genérico de Caminantes, uno de los posibles sentidos del ciclo, que no es otro que el del exilio.

Una de las claves sobre las que se asientan las conflictivas relaciones de Mira con España reside precisamente en la singular condición de exiliado que él proclamó, en especial a través de sus polémicas declaraciones, textos -Carta abierta al Ministro de Cultura, de 1989-9 y carteles que publicó en revistas nacionales e internacionales, como Así soy I Así me quiere España (1988), Arte o prostitución (1989), Víctor Mira like van Gogh (1989) o A mere crisis is not enough (1993). El título del lienzo debe interpretarse tanto desde esa posición personal como desde la coyuntura política de una España que, en 1981, negociaba incorporarse a la CEE, dentro del proyecto de homologación internacional impulsado por el reformismo de los primeros gobiernos tras la muerte de Franco. En el vocativo utilizado por Mira, Europa, escucha el canto de mi pueblo, se advierte el deseo del artista por apoyar la integración de España en el entorno democrático europeo, si bien la procesión de dobladas figuras que conforman ese pueblo español -violentadas por el exilio o por la dictadura- resultaba completamente anómala en el contexto de un país donde las instituciones culturales van a promocionar una pintura que no aludiera a la memoria del anterior régimen ni a las tensiones latentes en la propia transición política. Este lienzo de Mira se afirma, al igual que sucediera con el intento de golpe de Estado del 23-F en Acontecimientos ocurridos en Barcelona (1981, óleo sobre lienzo, 217 x $381 \mathrm{~cm}$. Col. particular), pintado en la misma época, como una reflexión, a través de la práctica pictórica, sobre la historia contemporánea. ${ }^{10}$

El conjunto de xilografías Caps (Fig. 7) se centra exclusivamente en el motivo de una cabeza que deriva de la de los Caminantes, como manifiesta su posición invertida y su grotesca fisonomía. Mira agudiza su carácter sígnico, al anular casi por completo el referente naturalista, y explora sus posibilidades formales, incorporando además otros símbolos que en esos momentos empiezan a formar parte decisiva de su vocabulario plástico, co-

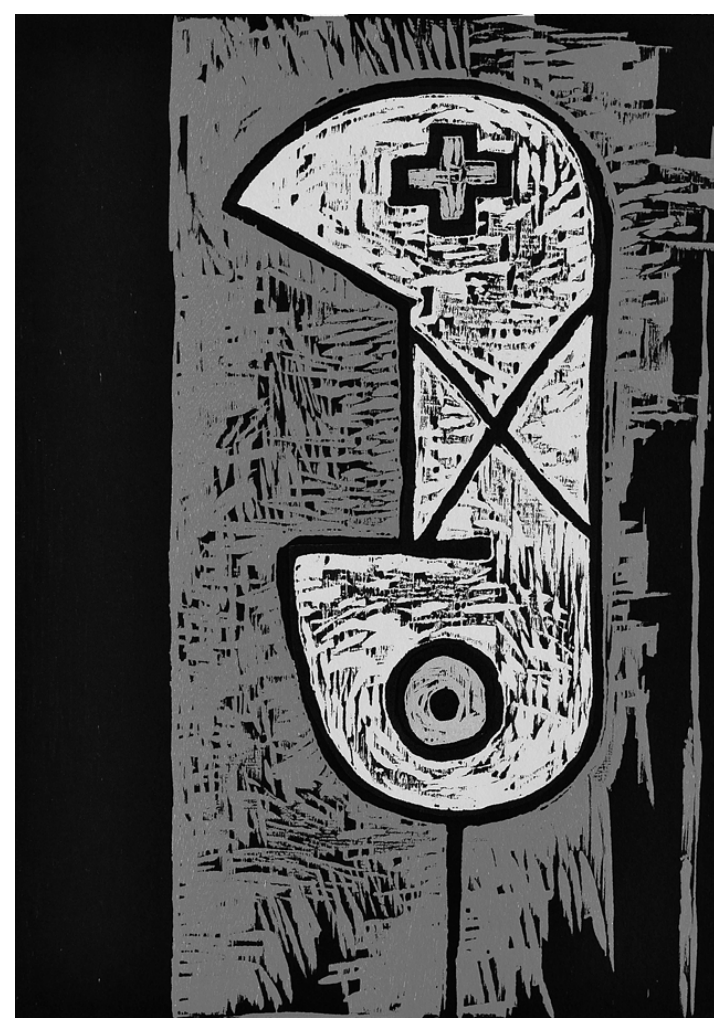

Fig. 7. Víctor Mira. Cap, 1983-1984, xilografía, 55 x 39.5 cm. Col. particular.

mo la cruz o un simplificado pájaro. El enérgico trabajo de la gubia sobre la matriz y los intensos colores planos exaltan la feroz agresividad y crispación que transmite su rictus. Si bien las escasas estampas que están fechadas indican los años 1983-1984, puede considerarse que estas variaciones en torno a la cabeza tienen su origen en las diversas alternativas exploradas y evaluadas por Mira en el proceso de dotar a la figura del caminante de su característica e hipertrofiada cabeza.

Aunque desde aproximadamente 1984 los caminantes, tal y como se formulan en esta serie, desaparecen de la obra de Mira, se percibe su continuidad en el motivo de las huellas, sobre el cual despliega varios ciclos, bien sean las pisadas coronadas con cruces de Montserrat o San Francisco Javier camino de Japón, en los que el caminante se convierte en peregrino, o el ya aludido El monje frente al mar bien temperado, sobre el lienzo de Friedrich Der Mönch am Meer (1808-1810, 110 x $171.5 \mathrm{~cm}$, óleo sobre lienzo. Alte Nationalgalerie, Berlín).

\footnotetext{
9 MIRA, Víctor. En España no se puede dormir. Barcelona: Galería Miguel Marcos, 2001, pp. 42-43.

10 Véase CORTÉS SANTAMARTA, David. "Una iconografía primigenia: el diálogo con el arte prehistórico en la obra de Víctor Mira". Anales de Historia del Arte, 2016, vol. 26, pp. 243-245.
} 


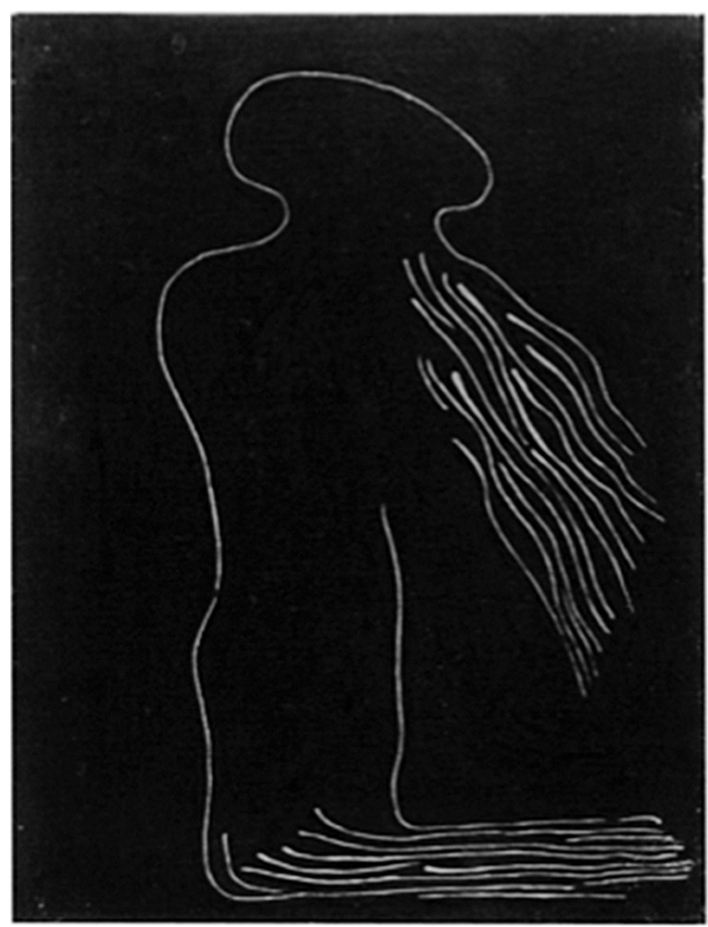

Fig. 8. Víctor Mira. Hombre de Hilatura, 1981, óleo sobre lienzo, 35 × $27 \mathrm{~cm}$. Col. particular.

\section{Ciclo Hilaturas}

En el ciclo Hilatura, las primeras versiones están pintadas en 1981 y se denominan aún Hombre de Hilatura. Se trata de pequeños óleos sobre lienzo (Fig. 8) donde la dimensión humana que el título propone se muestra en el fino y decidido grafismo que delinea el contorno de una figura erguida, en los que se distingue cabeza, piernas y espalda, pero de cuyos pies y tronco se desprende una multiplicidad de pequeñas y fragmentadas líneas que, en su leve, irregular y dúctil consistencia, remiten inmediatamente a hebras o hilos que hubieran sido cortados. Son esta última variedad de líneas las que habrán de ampliarse, multiplicadas en una estremecida insistencia, hasta configurar por completo la silueta de las hilaturas. Aún siendo una enunciación primera de las más complejas elaboraciones posteriores, es justo en la sencillez de este óleo donde se evidencia la importancia esencial que posee, por un lado, la línea y, por otro, la discontinuidad, como principios formales que determinan el ciclo. Las numerosas variantes que Mira realiza de las hilaturas parten, casi exclusivamente, de esos dos principios y de una exhaustiva combinación de las posibilidades implícitas en ellos, que además adquieren nuevas inflexiones a partir de las técnicas y los formatos empleados por el artista.
La analogía dominante en la serie, que propone de manera explícita la equivalencia entre una línea segmentada y un hilo cortado, moviliza a la vez la factura pictórica y las potencialidades semánticas de la imagen, intensificándose a lo largo del periodo de creación del conjunto, como exponen los propios títulos. Al inicial de Hombre de $\mathrm{Hi}$ latura, le sigue, en el mismo año de 1981, el de Hombres Hilatura, prescindiendo de la preposición e igualando ambos términos para, ya desde 1983, decantarse definitivamente por el nombre de Hilaturas. Las obras reflejan con exactitud ese mismo alejamiento de lo humano y el progresivo énfasis en la materialidad al que el trazo se asimila, de modo que el aspecto antropomorfo de los pequeños óleos da paso a imágenes mucho más depuradas, prácticamente abstractas, en los que es complicado discernir la referencia originaria, al estar ganadas en su totalidad por un discontinuo y trémulo grafismo. Cada uno de los trazos de Mira recompone la peculiar flacidez de un hilo cortado, su ausencia de tensión y aleatoria irregularidad, pero también su especial ductilidad, que se interrumpe en el leve y tenue giro en los extremos del hilo, allí donde se ha producido el corte. Como si la línea se activara, paradójicamente, gracias a la interrupción que la acota y suspende. Para obtener ese efecto plástico es necesaria una cierta disposición de la mano, que debe abandonarse a una suerte de fatiga para que soslaye en lo posible lo que pudiera haber de excesivamente resuelto en la propia ejecución pictórica, y que a la vez debe modular el incierto recorrido del grafismo para así componer, en una insistente multiplicidad, la figura completa de la hilatura.

Desde los surcos rasgados sobre la matriz de las xilografías estampadas entre 1984 y 1985, a los trayectos de la brocha en las pinturas de gran formato, que se van desvaneciendo sobre el lienzo hasta su total desaparición en las extremidades de la hilatura, el gesto de Mira asume una lasitud o desfallecimiento que genera un efecto visual tanto más fascinante cuanto que se conjuga con la obstinada reiteración del mismo. Es en esa insistencia, y no en cada uno de los trazos, donde reside el agitado estremecimiento que poseen las obras. Las líneas discontinuas se acumulan y entrecruzan, bien sea para formar estrictamente la silueta de la hilatura, como sucede en los dibujos y aguafuertes, bien sea para ocupar en su integridad la superficie del soporte, caso de las xilografías y de buena parte de los óleos. Sin embargo Mira evita que el enmarañamiento de líneas se unifique o agrupe en un contorno definido con firmeza que le dote de consistencia, puesto que lo 
que caracteriza a las hilaturas es, precisamente, la carencia de una presencia corporal plena. Mira propone la hilatura como un puro enunciado gráfico, de manera que los perfiles de su figura -la cual, por otra parte, se ajusta a un modelo muy codificado y resulta claramente reconocible- son ejecutados para que nunca se cierren terminantemente, hasta el punto de que a veces es el propio vacío, o la ausencia de intervención, lo que las delimita. En la factura de las xilografías se distingue con claridad ese procedimiento. Los trazos, segmentados e interrumpidos, se multiplican, desiguales y asistemáticos, y aunque a menudo se superponen, no llegan a unirse ni a clausurar un límite concluyente. De hecho la silueta de la hilatura resulta de la impresión de aquellas superficies de la plancha de madera que no han sido talladas, así como de las diversas áreas cromáticas que distinguen figura y fondo.

Este uso de la línea discontinua y multiplicada se relaciona con una de las técnicas de grabado empleadas en el arte prehistórico, calificada como "trazo múltiple estriado" y que se distingue por "perfilar el diseño con la sucesión de pequeñas incisiones cortas subparalelas no muy agrupadas, de manera que entre líneas quedan espacios libres". ${ }^{11}$ El ciclo Hilaturas, al igual que sucedía con el de Caminantes, deriva de las series prehistóricas, con las que se solapa cronológicamente. Por ello es frecuente que se establezcan resonancias y ecos formales entre ambos conjuntos. En algunas estampas previas al magno proyecto de Cien imágenes de África, contenidas en las carpetas Mediodía y Pequeña serie roja, ${ }^{12}$ la línea interrumpida y abierta, así como la flacidez de las concisas figuras humanas, recuerdan a las primeras hilaturas.

También se intuye otro posible ascendente para la serie, común a distintas obras de este periodo dentro de la trayectoria de Mira, como es la creación de Paul Klee. Las ilustraciones de Klee para Candide de Voltaire, de 1911,13 por las que Mira me comunicó su entusiasmo en diversas ocasiones (Fig. 9), están realizadas exclusivamente a partir de unas líneas deshechas y discontinuas, que el propio Klee calificaba de "garabatos fluctuantes" ${ }^{14}$ con unas palabras que serían asimismo aplicables para describir las hilaturas.

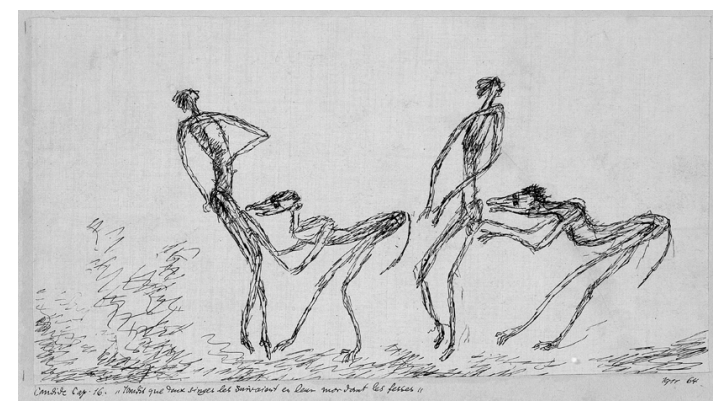

Fig. 9. Paul Klee. Ilustración para Candide.

Los personajes de las escenas de Klee poseen unos cuerpos filiformes y flexibles, de extraña inmaterialidad, y sus esquemáticas siluetas han sido dibujadas con un trazado cuyo nerviosismo posee la falsa apariencia de la inmediatez y la torpeza, como se adivina en una mirada más prolongada, que percibe el refinamiento tras esa fluencia lineal. Si bien el componente irónico de las ilustraciones de Klee, réplica del que emana del texto de Voltaire, está ausente en las hilaturas, es difícil negar el parentesco entre dos conjuntos de obras que exploran hasta sus últimas consecuencias las posibilidades plásticas inscritas en el uso de una línea interrumpida y múltiple.

La forma de las hilaturas asume, a lo largo del ciclo, distintas configuraciones. Al referido carácter antropomorfo de los Hombres de Hilatura le siguen los Hombres Hilatura, nombre con el que Mira designa una carpeta de estampas que contiene seis aguafuertes donde el motivo ya ha alcanzado una fórmula decisiva (Fig. 10). La inclinación, antes sólo latente, de la cabeza, se ha consumado de una manera extrema y es la curva que transcribe ese giro la que adquiere una importancia esencial en la estructura íntegra de la hilatura. Su cabeza será, a partir de ahora, una ambigua disposición de líneas descendentes que se asemejan a dos largos apéndices abatidos que están separados, en su bifurcación, por un grafismo. Éste parece no pertenecer a la propia figura, tan sólo sostiene la caída de una delicuescente sustancia. Las líneas no se unen en su parte inferior para constituir una forma cerrada, sino que el trazo se desvanece sutilmente, como el rastro residual de

\footnotetext{
11 SANCHIDRIÁN, José Luis. Manual de arte prehistórico. Barcelona: Ariel, 2001, p. 95.

12 Mediodía consta de seis aguafuertes en relieve de 24.5 x $16 \mathrm{~cm}$, estampados en 1982; la carpeta Pequeña serie roja contiene cinco aguatintas de $23.8 \times 15.8 \mathrm{~cm}$ fechadas en 1982-1983.

13 Las ilustraciones fueron publicadas en 1920, acompañando la traducción al alemán del texto de Voltaire. Kandide, oder, Die beste Welt: eine Erzahlung. Múnich: Kurt Wolff, 1920.

14 KLEE, Paul. Diarios. México: Era, 1970, p. 304.
} 


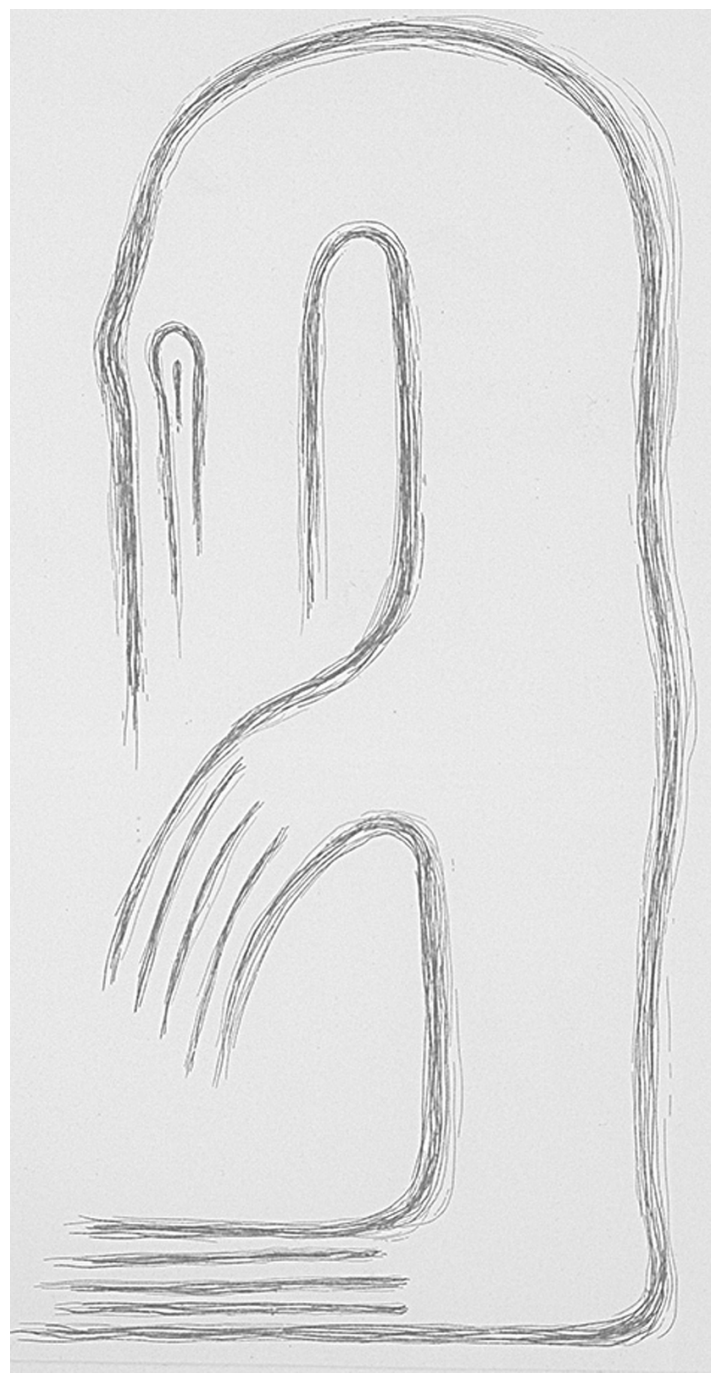

Fig. 10. Víctor Mira. Hombre bilatura, 1982, aguafuerte, $31.5 \times 25 \mathrm{~cm}$. Col. particular.

una materia que terminará por agotarse. La imposibilidad de distinguir con exactitud la conformación de lo que debería corresponderse con la cabeza de la hilatura es lo que las proporciona un intenso sentido enigmático. La desaparición, en el título, de la palabra "hombre" no hará sino acentuar la misteriosa presencia de unos seres que, al igual que ciertos seres de las series prehistóricas de Mira, se ubican en un indiscernible devenir entre las categorías de lo humano, lo animal y lo objetual. Las extremidades, aún reducidas a un proceso similar, resultan más reconocibles. Incluso en su número aluden a dedos humanos. El motivo, emplazado en el centro, es un grafismo lineal que posee la exclusiva materialidad de la blancura del papel sobre el que está impreso.

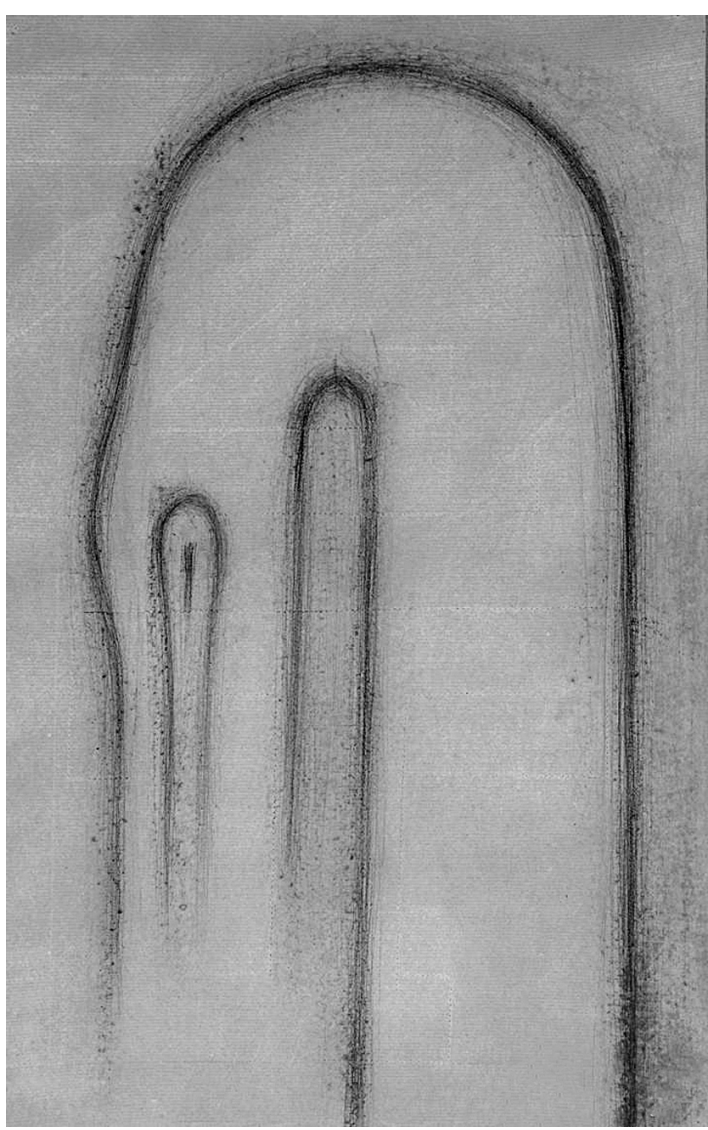

Fig. 11. Víctor Mira. Hombre hilatura, 1983, grafito y tiza sobre papel, $60 \times 49 \mathrm{~cm}$. Col. particular.

Realizada con unos medios que subrayan su desvaído y exangüe aspecto, como son el grafito y la tiza, una variante posterior responde a esa voluntad de depuración que guía el ciclo, manifestándose en términos aún más radicales (Fig. 11). Prácticamente abstracta, en ella han desaparecido por completo brazos o piernas y los trazos se articulan en torno a la doble curvatura que remite a la torsión germinal de la figura. Los dos extremos de esa laxa sustancia se desvanecen por igual. La hilatura, pues, como puro residuo.

Un conjunto de xilografías a color, estampadas en 1984 y 1985 (Figs. 2 y 12), recuperan las distintas variantes, pero sometidas a unas nuevas modulaciones debido a la técnica empleada. Mira, que ya había experimentado con este método de grabado anteriormente, elabora en ellas un lenguaje gráfico que logra desprenderse de los vehementes efectos expresivos -quebrados y agudos perfiles, huella de la talla, rotundos contrastes- con los que se identificaba la xilografía desde que los miembros del grupo Brücke la utilizaron como medio predilecto de sus concepciones. ${ }^{15}$ Quizá

${ }^{15}$ Véase BARRON, Stephanie et al., German Expressionist Prints and Drawings. Múnich: Prestel / Los Ángeles: LACMA, 1989. 
sean éstas las versiones de las hilaturas en las que la cadencia del singular trazo de Mira alcance su plasmación ideal. Las marcas que deja el obstinado paso del buril por la matriz, los ataques al iniciar la talla o los leves cambio de presión a lo largo de su recorrido se asemejan a rasguños, muy distintos de las angulosas y violentas formas astilladas de la xilografía expresionista.

De igual manera, la huella de las irregularidades naturales de la matriz, aunque deudora de aquéIla, se deposita sobre el papel, superponiéndose al trazado lineal, más a modo de una delicada textura que de una materialidad ruda. Si el ciclo había estado ganado por unos colores tenues y apagados, las estampas exhiben, por el contrario, un cromatismo vivaz, que pronto habrá de trasladarse asimismo a los grandes óleos y que plantean un inédito contraste con la precaria consistencia de las hilaturas. Algunas de las xilografías incorporan además el motivo del corazón, como un sencillo ideograma convencional que, o bien se sitúa en el interior de la figura o bien se convierte en singular asiento de la misma. A veces (Fig. 12) el corazón está atravesado por un puñal, imagen que se inscribe en las representaciones del Sagrado Corazón de María tal y como se establecieron en la devoción cristiana desde época medieval, ${ }^{16}$ pero que también recogen gráficamente los versos del propio artista que inician su poema Apuñalado: "Un corazón no es nada / si no está apuñalado". ${ }^{17}$

En el ideograma se combinan, pues, las religiosas connotaciones sacrificiales -realzadas además al integrar Mira dos cruces en su interior- con la referencia al corazón como símbolo popular para manifestar las emociones, especialmente el amor. ${ }^{18}$ Otras obras proponen una nueva declinación de ambos motivos, de modo que los corazones están formados a partir del encuentro simétrico de dos hilaturas que se contraen y se pliegan sobre sí mismas generando con sus apéndices un diagrama que simula las cavidades internas del órgano. Tanto el puñal como el corazón escindido acentúan el sentido lacerado, o desgarradura, que convocan las hilaturas, así como el dolor que las subyuga. $Y$ es que, en un uso metafórico del término que las designa, se diría que éstas son cria-

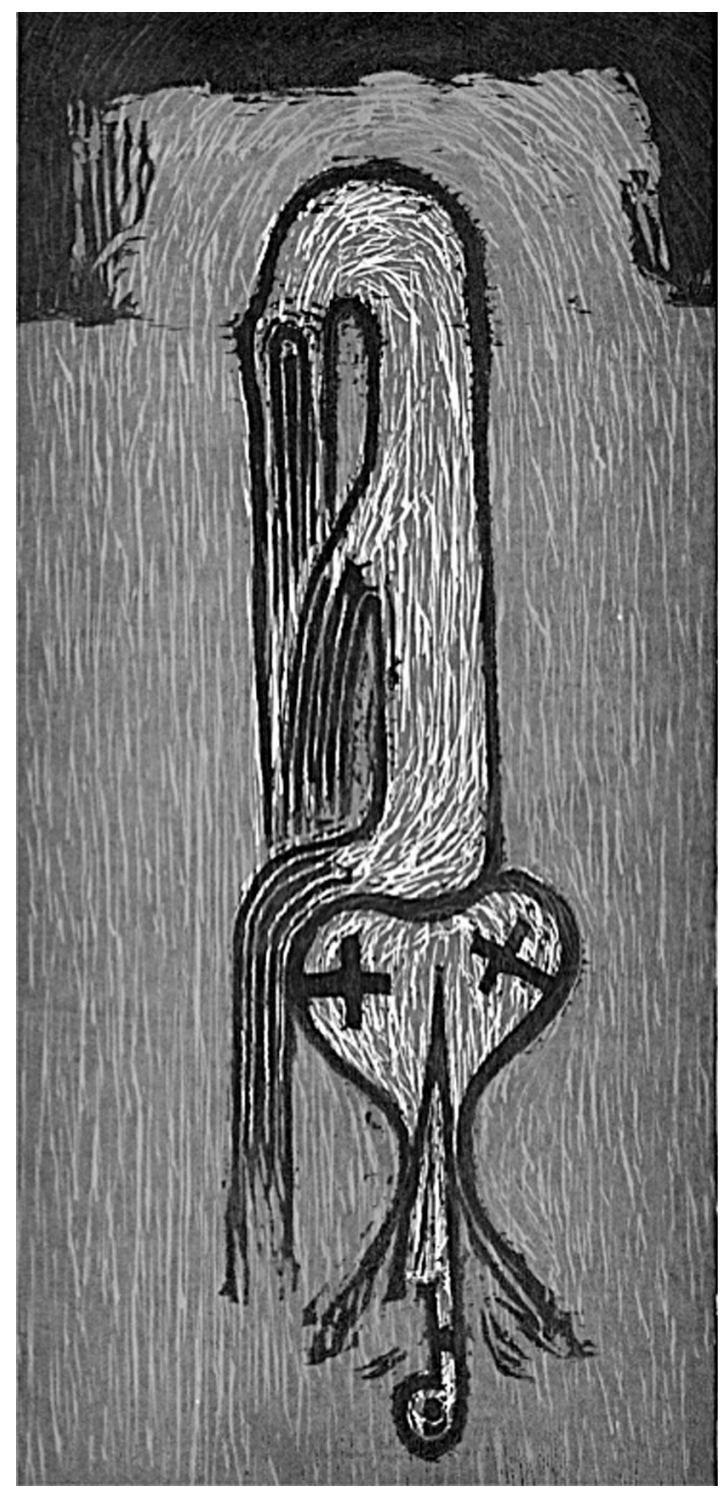

Fig. 12. Víctor Mira. Hilatura, 1984, xilografía, 58 x $28 \mathrm{~cm}$. Col. particular.

turas deshilachadas, conformadas no como un tejido entrelazado o estructurado, sino por una acumulación contingente de numerosas hebras o pedazos de hilo cortados, que no llegan a adquirir solidez alguna.

Quizá sea en el ámbito de la literatura donde se pueda descubrir la invención que guarda más similitudes con las hilaturas de Mira. Desde su ju-

\footnotetext{
${ }^{16}$ Lucas 2:35 "Y una espada atravesará tu alma, para que se descubran los pensamientos de muchos corazones". Sobre la representación convencional del corazón véase el texto "The Heart", incluido en KEMP, Martin. How Image Becomes Icon. Oxford: Oxford University Press, 2011, pp. 81-110.

17 Poema escrito en 1979 e incluido en la antología poética MIRA, Víctor. El poeta muerto 1972-1990. Madrid: Ediciones Libertarias, 1995, p. 95.

${ }^{18}$ Esa ambigua duplicidad se mantiene en numerosas obras de Mira, si bien en algunas series, como las estampas que componen las Imágenes para enamorados (1985), los Sonetti lussuriossi di Pietro Aretino (1989) o en los óleos y estampas de Montjuich (1990) los corazones adquieren un sentido más netamente erótico y aún sexual.
} 


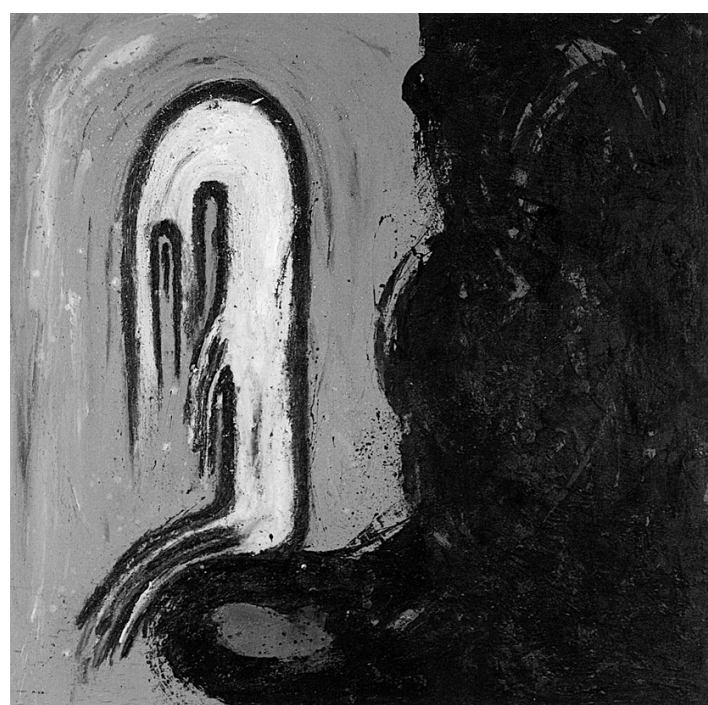

Fig. 13. Víctor Mira. Hilatura, 1985, óleo sobre lienzo, 195 x 195 cm. Col. Cortes de Aragón.

ventud, Mira fue un ávido lector de Kafka, hasta convertirse en una de sus referencias literarias, como confirma el hecho de que incluyera una de sus frases -"Hay una meta, pero no un camino; lo que llamamos camino son vacilaciones"- para acompañar uno de los aguafuertes, Muletas de filósofo, del libro de estampas Axiomas (1994). A pesar de que no sea posible afirmar una influencia directa del relato Die Sorge des Hausvaters, en la concepción de las hilaturas, el párrafo en el que Kafka describe la extraña criatura llamada Odradek resulta extraordinariamente próximo a éstas: "A primera vista se asemeja a un carrete de hilo plano y en forma de estrella, y, de hecho, también parece que estuviera recubierto de hilo; aunque a decir verdad solo podría tratarse de trozos de hilo viejos y rotos, de los más diversos tipos y colores, anudados entre sí, pero también inextricablemente entreverados". ${ }^{19}$

La similitud opera en varios sentidos. No sólo en la apariencia de ambos seres -las líneas de las hilaturas se asemejan a esos "trozos de hilo viejos y rotos" que recubren a Odradek- sino también en la dificultad para describirlos con más precisión. El hermetismo de la narración de Kafka ha estimulado innumerables exégesis a las que, finalmente, se resiste, ${ }^{20}$ por lo que no se trataría tanto de en- contrar una, improbable, clave interpretativa al texto y a la imagen cuanto de señalar cómo las hilaturas comparten con Odradek unos elementos comunes. Por un lado su indistinción -no son propiamente un objeto, ya que están dotados de vida, pero tampoco son humanos ni animales- $y$ por otro su estatuto incumplido y residual. Es este último aspecto el que determina de manera esencial las obras de Mira. Incapacitadas para adquirir una consistencia definitiva, las hilaturas son seres vulnerados que no llegan a desarrollarse con plenitud. Una subjetividad frustrada y excluida. Todos los recursos formales desarrollados por el artista convergen para trasladar plásticamente esa condición: desde el singular ductus de las líneas y sus discontinuidades a las agotadas configuraciones de unas criaturas que, a pesar de su flacidez, perseveran y se mantienen erguidas, aún en su curvada torsión. En ocasiones se sitúan al borde de una especie de precipicio -análogo a los corazones apuñalados de otras variantes- creado por unas poderosas pinceladas negras que amenazan con engullirlas (Fig. 13). Ganadas por el dolor, pero sin sucumbir por completo a él.

De hecho, lo que distingue a las hilaturas del resto de figuras atormentadas de la producción de Mira, como los propios Caminantes, es la ausencia de todo evidente o violento dramatismo. Si la dislocada cabeza de aquellos parecía registrar la inextinguible errancia del exilio, en el caso de las hilaturas su sustancia exánime no es sino la forma constitutiva de una existencia fracturada y marginal, que se encoge sobre sí misma y se activa en la agitación de sus interrumpidos trazos, cada uno de los cuales es tanto el vestigio de una exclusión como, a la vez, la señal de una resistencia última.

Si en otros ciclos de Mira -sobre todo en Interiores catalanes con tomate, de la década de 1970, y en Moods e Imágenes binoculares, pintados en los años previos a su suicidio- lo biográfico se plasmaba de un modo directo, incluso abiertamente documental, en los ciclos Caminantes e Hilaturas cabría interpretar asimismo el íntimo malestar que atraviesa las figuras como un trasunto del que dominaba al propio autor: en el replegarse de las hilaturas se percibe la huidiza soledad de Mira, en el crispado vagar de los caminantes se adivinan sus viajes y su conciencia de expatriado.

\footnotetext{
19 KAFKA, Franz. "La preocupación del padre de familia". Narraciones y otros escritos. Barcelona: Galaxia Gutenberg, 2003, p. 203.

20 Para una somera revisión de las mismas véanse las notas de Jordi Llovet en KAFKA, 2003, pp. 1030-1032.
} 